\title{
Early-onset type 2 diabetes in a Mexican survey. Results from the National Health and Nutrition Survey 2006
}

\author{
Aída jiménez-Corona, PhD, (1) Rosalba Rojas, PhD, (1) Francisco J Gómez-Pérez, M Esp, ${ }^{(2)}$ \\ Carlos A Aguilar-Salinas, M Esp. ${ }^{(2)}$
}

\begin{abstract}
Jiménez-Corona A, Rojas R, Gómez Pérez FJ,Aguilar-Salinas CA. Early-onset type 2 diabetes in a Mexican survey: Results from the National Health and Nutrition Survey 2006. Salud Publica Mex 2010;52 suppl I:S27-S35.
\end{abstract}

\begin{abstract}
Objective. To describe the characteristics of patients with type 2 diabetes diagnosed before age 40 (early-onset type 2 diabetes) identified in a nation-wide, population-based study. Materials and Methods. The survey was done in Mexico during 2006. Medical history, anthropometric and biochemical measurements were obtained in every subject. Results. Cases diagnosed before $(n=|8|)$ and after age $40(n=659)$ were included. Early-onset type 2 diabetes was present in $13.1 \%$ of the previously diagnosed, $30.3 \%$ of the cases identified during the survey and $21.5 \%$ of the whole population with diabetes. These individuals had a greater prevalence of obesity and hypertriglyceridemia compared to the cases diagnosed after age 40. Conclusions. Early-onset type 2 diabetes was present in $21.5 \%$ of patients with type 2 diabetes in Mexico. Close to $70 \%$ of them were obese or overweight and had the clinical profile of the metabolic syndrome.
\end{abstract}

Key words: diabetes mellitus; obesity; hyperglycemia; insulin; Mexico
Jiménez-Corona A, Rojas R,

Gómez Pérez FJ,Aguilar-Salinas CA.

Diabetes tipo 2 de inicio temprano en una encuesta nacional: Resultados de la Encuesta Nacional de Salud y Nutrición 2006. Salud Publica Mex 2010;52 supl I:S27-S35.

\section{Resumen}

Objetivo. Describir las características de los pacientes con diabetes diagnosticados antes de los 40 años en una encuesta representativa de la población mexicana. Material y métodos. La encuesta fue realizada en México durante 2006. Se registró la historia médica, mediciones antropométricas y bioquímicas de los participantes. Resultados. Se incluyeron casos diagnosticados antes $(n=|8|)$ y después $(n=659)$ de los 40 años. La diabetes tipo 2 de inicio temprano está presente en $13.1 \%$ de los casos previamente diagnosticados, $30.3 \%$ de los identificados durante la encuesta y en $21.5 \%$ de la población total con diabetes. En los casos diagnosticados antes de los 40 años hay una prevalencia mayor de obesidad e hipertrigliceridemia que en los diagnosticados después de los 40. Conclusiones. La diabetes de aparición temprana está presente en $21.5 \%$ de los casos con diabetes en México. Setenta por ciento de ellos tenían un peso mayor al saludable y tenían el perfil clínico del síndrome metabólico.

Palabras clave: diabetes mellitus; obesidad; hiperglicemia; insulina; México

(I) Instituto Nacional de Salud Pública. Cuernavaca, Morelos, Mexico.

(2) Instituto Nacional de Ciencias Médicas y Nutrición Salvador Zubirán. Mexico City, Mexico 
$\mathrm{T}^{\mathrm{s}}$ pe 2 diabetes has a remarkable social and economical impact in Mexico. ${ }^{1}$ The large and growing number of cases, the complexity of therapy and the coexistence of several co-morbidities are major determinants of the burden imposed by this disorder to our health system. In countries, like Mexico, in which diabetes is highly prevalent, the onset of the disease happens at earlier ages. ${ }^{2}$ This feature boosts the adverse consequences of diabetes. The longer exposure to hyperglycemia and other diabetes-related abnormalities increase the likelihood that patients will develop chronic complications. ${ }^{3}$ This characteristic results in a large number of incapacitated before the age of 50 . Also, these subjects frequently exhibit a more severe form of the disease and require insulin treatment at an earlier time. ${ }^{4}$ In addition, they have different needs and obstacles to achieve adherence to therapy. This subset of patients, referred, as earlyonset type 2 diabetes, is a heterogeneous group. Analysis of the 1994 National Survey of Chronic Diseases (ENEC) showed that early-onset type 2 diabetes occurred in $14 \%$ of the Mexican population with diabetes. ${ }^{5}$ The majority of the cases $(78 \%)$ had one or more traits of the metabolic syndrome and were either obese or overweight. The remaining cases $(22 \%)$ had a clinical profile seen in insulin deficient states (i.e., maturity onset diabetes of the young or late-onset autoimmune diabetes).

Few papers have described the characteristics and the consequences of diabetes diagnosed between ages 20 and 40. ${ }^{6-11}$ Nation wide, population-based studies are required to describe the unbiased prevalence and the characteristics of the patients with early-onset type 2 diabetes. The objective of this report is to update the information provided by the National Survey of Chronic Diseases (ENEC), using data of the Mexican National Health and Nutrition Survey 2006 (ENSANUT 2006).

\section{Material and Methods}

\section{Population sample}

The objectives and design of the survey are described in detail in another report of this issue. In brief, this is a cross sectional study that is representative of individuals living in metropolitan areas (state capitals or cities with a population above 100000 people), urban (population 2500 to 99999 inhabitants) and rural settings (less than 2500 inhabitants). A multistage, stratified and probabilistic sampling procedure was used. The country was divided in four regions (northeast, northwest, central and southern). All states of Mexico were included. A random sample of Basic Geographical Statistical Units was obtained in each state. Neighborhood blocks were randomly selected. In every home one randomly selected adult, adolescent and infant and health service user were invited to participate. Military, religious, health and other institutions were excluded. A target of 4731 individuals and 1476 households per state was estimated for every state. The sample size was considered capable of detecting risk factors at the state level, that have at least a prevalence of $8.1 \%$ with a relative error of estimation of 0.25 , a design effect of 1.7 and a non-response rate of $20 \%$. The number of households was increased to 1620 in 13 states to assure enough power to be representative for the communities participating in the "Oportunidades" federal program. The total amount of households was 48 600. This sample size allows the assessment of conditions with a prevalence equal or greater than $0.4 \%$. The study was realized in accordance with the Helsinki Declaration of Human Studies. Informed consent was obtained of each participant. A separate consent form was signed by participants that provided blood samples. The research and ethics committees of the Instituto Nacional de Salud Pública approved the study protocol.

\section{Personal interview}

A general structured interview was conducted. A previously standardized questionnaire was used to obtain information on demographic and socioeconomic aspects, family health history, personal medical history, and lifestyle factors such as smoking. It includes questions about pre-diagnosed hypercholesterolemia and hypertriglyceridemia and the current use of hypolipidemic agents. In the same visit, anthropometric and blood pressure measurements were obtained. Systolic (1st-phase) and diastolic (5th-phase) blood pressures were measured to the nearest even digit with a sphygmomanometer with the subject in the supine position after a 5 minutes rest using a mercurial sphygmomanometer. Participants removed their shoes and upper garments. Height was measured to the nearest $0.5 \mathrm{~cm}$ using a stadiometer. Body weight was measured on a daily calibrated digital balance and recorded to the nearest $0.1 \mathrm{Kg}$. Body mass index (BMI) was calculated as weight $(\mathrm{Kg})$ divided by height $\left(\mathrm{m}^{2}\right)$ and was used as an index of overall adiposity. ${ }^{12}$ The equipments were regularly calibrated using reference samples provided by the manufacturer.

\section{Methods}

Blood samples were obtained in approximately $30 \%$ of the adult population. A random sub-sample, with 8 or more hours of fasting, was obtained $(n=6$ 006). These cases were randomly distributed between study 
subjects from the total fasting cases, with statistical power to detect prevalence of DM2 and dyslipidemias $\geq 8 \%$, and balanced by geographic region. All analytical measurements were done at the Instituto Nacional de Salud Pública. The sampling procedure was standardized during a two week training course. The subjects were sampled at their homes; they remained sited for five minutes before the blood was drawn.

Total cholesterol was determined using enzymatic hydrolysis and oxidation. Triglycerides concentration was measured after lipase hydrolysis in an automatic analyzer with a tungsten lamp. The interassay CV was $3.04 \%$ for total cholesterol and $5.7 \%$ for triglycerides. HDL- cholesterol was measured by an enzymatic colorimetric direct method after eliminating chylomicrons, VLDL, and LDL by enzymatic digestion; the interassay C.V. was $5.02 \%$. To assure the precision and exactitude of the determinations, the concentrations of total cholesterol, HDL-cholesterol and triglycerides were adjusted to a standard curve constructed with the determinations of the NIST materials $909 \mathrm{~b}$ and 1951b, levels I and II, using the standard material and a 1:1 dilution

\section{Definitions}

Diabetes was considered present in previously diagnosed cases or if a fasting plasma glucose was equal or greater than $126 \mathrm{mg} / \mathrm{dl} .{ }^{13}$ In the early-onset type 2 diabetes group were included cases diagnosed between ages 20 and 40 years. The body mass index was used to define overweight $\left(25-30 \mathrm{~kg} / \mathrm{m}^{2}\right)$ and obesity $\left(\geq 30 \mathrm{~kg} / \mathrm{m}^{2}\right)$.

Hypertriglyceridemia was defined as a fasting plasma concentration $\geq 150 \mathrm{mg} / \mathrm{dl}$. Cholesterol $\geq 200$ $\mathrm{mg} / \mathrm{dl}$ was considered to be hypercholesterolemia. High density lipoprotein cholesterol (HDL) concentration was considered to be abnormal if it was less than $<40 \mathrm{mg}$ / $\mathrm{dl}$ for men and $<50 \mathrm{mg} / \mathrm{dl}$ for women. These cut-off points were selected based on the National Cholesterol Education Program recommendations. ${ }^{14}$ Hypertension was diagnosed when the systolic pressure was $\geq 140 \mathrm{~mm}$ $\mathrm{Hg}$ and/or diastolic pressure was $\geq 90 \mathrm{~mm} \mathrm{Hg}$ and/ or current use of antihypertensive medications. Blood pressure was measured twice in two different visits if the initial measurement was $\geq 120 / 80$. Regular alcohol consumption was defined as having 10 or more drinks per week during the previous month. Smoking was defined as having one or more cigarettes during the last thirty days.

\section{Statistical analysis}

The database was validated through recognition of missing values, outliers and inconsistencies between variables. Prevalence of diabetes in indigenous and non-indigenous population according with several risk factors was estimated. The association between several risk factors and prevalence of diabetes was examined by multiple logistic regression. The model included age group ( $>$ or $<40$ years), gender, ethnicity (classified as speaking any indigenous language, non-speaking indigenous language and non indigenous) and the variables under study. On the basis of the sample design of the survey, we used individual weighted factors in the statistical analysis and considered the survey's complex sampling design to obtain variances. Data from the 2005 National Population Counting was used to estimate the number of cases nationwide. All analyses were conducted using Stata 9.

\section{Results}

The clinical characteristics of the subsample with 8 or more hours of fasting ( $\mathrm{n}=6$ 006) are shown in table I. Data are presented for subjects younger or older than age 40 . The younger individuals had a higher education. However, they appertained more often to the lowest socioeconomic strata and a greater percentage of them had regular consumption of alcohol and smoking. Their mean body mass index was $27 \mathrm{~kg} / \mathrm{m}^{2}$. As expected, their prevalence of high blood pressure and dyslipidemia was lower compared to the older group.

The prevalence of diabetes in the study sample and in several subsets of the population is shown in table II. The national overall prevalence of diabetes was $14.42 \%$. The coexistence of obesity, low HDL cholesterol, hypertriglyceridemia and arterial hypertension was associated with a higher prevalence of diabetes. The prevalence of diabetes in subjects aged 40 or younger was $5.8 \%$. Early-onset type 2 diabetes was present in $13.1 \%$ of the previously diagnosed, $30.3 \%$ of the cases identified during the survey and $21.5 \%$ of the whole population with diabetes. Using expanding factors, we estimate that there are 1662870 Mexicans with earlyonset type 2 diabetes.

The clinical profile of the early-onset type 2 diabetes group is shown in table III. The results are presented for cases previously diagnosed or identified as affected during the survey for both young and older patients with diabetes. All cases were considered as type 2 diabetes. Ethnicity was not different between the early- or late-onset groups. The early-onset group had a higher education compared to the older patients with diabetes, but this feature was not associated with a higher income. A large percentage live in urban centers and almost a third were in the lowest income groups. Current smoking and alcoholism were more common 
Table I

Description of the study population. Mexico, ENSANUT 2006

\begin{tabular}{|c|c|c|c|}
\hline & $\begin{array}{l}\text { Aged } 40 \text { years and younger } \\
\qquad(n=3 / 28)\end{array}$ & $\begin{array}{l}\text { Older than } 40 \text { years of age } \\
\qquad(n=2878)\end{array}$ & $p$ value \\
\hline Sex (men), \% & 45.8 & 47.0 & 0.553 \\
\hline Age (mean, s.e.) & $29.3(0.2)$ & $55.7(0.3)$ & $<0.001$ \\
\hline \multicolumn{4}{|l|}{ Schooling, \% } \\
\hline None or basic school & 33.1 & 70.5 & $<0.001$ \\
\hline Middle & 35.9 & 16.7 & \\
\hline High school or high & 31.0 & 12.9 & \\
\hline \multicolumn{4}{|l|}{ Size of locality, \% } \\
\hline Rural & 19.9 & 22.2 & 0.097 \\
\hline Urban & 24.0 & 24.4 & \\
\hline Metropolitan area & 56.1 & 53.4 & \\
\hline \multicolumn{4}{|c|}{ Socioeconomic income deciles, \% } \\
\hline $1-2$ & 40.9 & 31.6 & 0.001 \\
\hline $3-4$ & 22.4 & 27.1 & \\
\hline $5-7$ & 27.2 & 30.6 & \\
\hline $8-10$ & 9.5 & 10.7 & \\
\hline
\end{tabular}

Ethnicity, \%

\begin{tabular}{|c|c|c|c|}
\hline Speaking any indigenous language & 5.3 & 6.3 & 0.922 \\
\hline Non-speaking indigenous language & 13.5 & 13.1 & \\
\hline Non-indigenous & 81.3 & 80.6 & \\
\hline Current smoking, \% & 21.1 & 16.4 & 0.004 \\
\hline Alcoholism, \% & 36.8 & 28.0 & $<0.001$ \\
\hline Body mass index $\left(\mathrm{kg} / \mathrm{m}^{2}\right)$ & $27.0(0.1)$ & $28.8(0.2)$ & $<0.001$ \\
\hline Systolic blood pressure, $\mathrm{mmHg}$ & $\mathrm{II} 7.4(0.5)$ & I29.1 (0.6) & $<0.001$ \\
\hline Diastolic blood pressure, $\mathrm{mmHg}$ & $77.6(0.5)$ & $82.3(0.6)$ & 0.001 \\
\hline Cholesterol, mg/d* & $191.5(1.5)$ & $209.4(1.7)$ & $<0.001$ \\
\hline \multicolumn{4}{|l|}{ HDL-C, mg/d** } \\
\hline Men & $37.2(0.4)$ & $37.7(0.4)$ & 0.394 \\
\hline Women & $40.0(0.4)$ & $41.8(0.4)$ & 0.002 \\
\hline LDL-C, mg/d** & $95.0(1.0)$ & $105.3(1.1)$ & $<0.001$ \\
\hline LDL-C $\geq 100 \mathrm{mg} / \mathrm{dl}, \%$ & 38.0 & 49.4 & $<0.001$ \\
\hline VLDL-C, mg/dI* & $22.2(0.3)$ & $25.3(0.3)$ & $<0.001$ \\
\hline Triglycerides, mg/dl* & $128.4(1.8)$ & $146.3(2.0)$ & $<0.001$ \\
\hline Hypertension, \% & 20.5 & 46.9 & $<0.001$ \\
\hline
\end{tabular}

The study was done in Mexico during 2006

All values are means and standard error (s.e.), except when indicated

Weighted sample 50759 I 42:28 729522 subjects aged 40 years and younger and 22029620 subjects older than 40 years of age $* N=5660,2703$ subjects aged $\leq 40$ years and 2957 subjects aged $\leq 40$ years 
Table II

Prevalence (\%) of diabetes in subjects aged 40 years and younger and subjects older than 40 years of AGE. MeXico, ENSANUT 2006

\begin{tabular}{|c|c|c|c|}
\hline & $\begin{array}{c}\text { Aged } 40 \text { years and younger } \\
(n=3 / 28) \\
\text { Prevalence }(95 \% \mathrm{Cl})\end{array}$ & $\begin{array}{c}\text { Older than } 40 \text { years of age } \\
(\mathrm{n}=2878) \\
\text { Prevalence }(95 \% \mathrm{Cl})\end{array}$ & $p$ value \\
\hline Total prevalence & $5.8(4.4-7.1)$ & $25.7(23.0-28.3)$ & $<0.001$ \\
\hline Self-reported & $1.6(1.0-2.2)$ & $14.8(|2.5-| 7 . \mid)$ & $<0.001$ \\
\hline Diagnosed during the survey & $4.2(2.9-5.4)$ & $10.9(9.1-12.6)$ & $<0.001$ \\
\hline \multicolumn{4}{|l|}{ Sex } \\
\hline Men & $6.4(4.0-8.8)$ & $27.8(23.7-32.0)$ & $<0.001$ \\
\hline Women & $5.3(3.9-6.7)$ & $23.8(20.4-27.1)$ & $<0.01$ \\
\hline \multicolumn{4}{|l|}{ BMI } \\
\hline Normal & $4.1(1.9-6.4)$ & $19.3(\mid 4.5-24.1)$ & $<0.001$ \\
\hline Overweight & $5.0(3.2-6.8)$ & $27.8(23.5-32.1)$ & $<0.001$ \\
\hline Obesity & $9.4(6.1-12.6)$ & $27.0(22.4-31.7)$ & $<0.001$ \\
\hline \multicolumn{4}{|l|}{ Cholesterol mg/d* } \\
\hline$\geq 200$ & $4.7(3.3-6.0)$ & $22.2(\mid 8.8-25.6)$ & $<0.001$ \\
\hline$<200$ & $4.7(2.6-6.7)$ & $23.8(20.4-27.2)$ & $<0.001$ \\
\hline \multicolumn{4}{|l|}{ HDL-C mg/d* } \\
\hline$<40$ in men and $<50$ in women & $5.6(3.8-7.3)$ & $25.7(22.3-29.1)$ & $<0.001$ \\
\hline$\geq 40$ in men and $\geq 50$ in women & $3.2(2.0-4.5)$ & $19.3(16.0-22.7)$ & $<0.001$ \\
\hline \multicolumn{4}{|l|}{ LDL-C mg/d|* } \\
\hline$\geq 100$ & $4.5(2.8-6.1)$ & $21 . I(I 7.9-24.4)$ & $<0.001$ \\
\hline$<100$ & $4.8(2.8-6.1)$ & $24.8(21.3-28.3)$ & $<0.001$ \\
\hline \multicolumn{4}{|l|}{ Triglycerides mg/dl* } \\
\hline$\geq 150$ & $8.2(4.7-11.8)$ & $29.0(24.5-33.4)$ & $<0.001$ \\
\hline$<150$ & $4.0(2.5-4.5)$ & $19.4(16.6-22.2)$ & $<0.001$ \\
\hline \multicolumn{4}{|l|}{ Hypertension } \\
\hline Yes & $7.8(4.8-10.4)$ & $30.9(27.1-34.7)$ & $<0.001$ \\
\hline No & $5.2(3.7-6.7)$ & $21.0(17.3-24.8)$ & $<0.001$ \\
\hline
\end{tabular}

The study was done in Mexico during 2006

$N=5660,2703$ subjects aged $\leq 40$ years and 2957 subjects aged $\leq 40$ years

in the early-onset group, but this difference did not reach statistical significance. Almost seventy percent $(n=125)$ of the early-onset group were newly identified cases. The undiagnosed cases were remarkably young (mean age 31.4 years); they were the group in which obesity, smoking and alcoholism were more common. Some co-morbidities, such as arterial hypertension and hypercholesterolemia were more common in the older cases. In contrast, the early-onset group had a higher prevalence of hypoalphalipoproteinemia.

More than two thirds of early-onset cases had a body mass index above $25 \mathrm{~kg} / \mathrm{m}^{2}$. Excess body weight (i.e., BMI $>25 \mathrm{~kg} / \mathrm{m}^{2}$ ) was associated with a higher prevalence of high blood pressure $(32.5 \%$ vs. $18.9 \%$ respectively, $p<0.05)$, low HDL cholesterol (79.3 vs. 61.7\% respectively, $p<0.05)$ and the coexistence of two or more 
Table III

Characteristics of finding and Self-Reported diabetic subjects by AGe CATEgory. MeXico, ENSANUT 2006

\begin{tabular}{|c|c|c|c|c|c|c|}
\hline & \multicolumn{3}{|c|}{ Cases found during the survey $(n=4 I 2)$} & \multicolumn{3}{|c|}{ Self-reported diabetic subjects $(n=428)$} \\
\hline & Aged $\leq 40$ years & Aged $>40$ years & & Aged $\leq 40$ years & Aged $>40$ years & \\
\hline & $n=125$ & $n=287$ & $p$ value & $n=56$ & $n=372$ & $p$ value \\
\hline Sex (men), \% & 58.3 & 57.4 & 0.916 & 30.4 & 46.1 & 0.114 \\
\hline Age (mean, s.e.) & $31.4(0.9)$ & $56.8(0.8)$ & $<0.001$ & $35.2(0.7)$ & $57.9(0.9)$ & $<0.001$ \\
\hline \multicolumn{7}{|l|}{ Schooling, No. (\%) } \\
\hline None or basic school & $60(29.1)$ & $208(65.1)$ & $<0.001$ & $30(50.0)$ & $301(77.0)$ & 0.030 \\
\hline Middle & $42(46.4)$ & $44(20.7)$ & & $16(33.4)$ & $36(9.6)$ & \\
\hline High school or high & $23(24.4)$ & $33(14.2)$ & & $10(16.6)$ & $34(13.4)$ & \\
\hline \multicolumn{7}{|l|}{ Size of locality, No. (\%) } \\
\hline Rural & $34(17.7)$ & $57(12.6)$ & 0.309 & $13(17.5)$ & $93(15.5)$ & 0.889 \\
\hline Urban & $4 \mathrm{I}(30.0)$ & $114(28.2)$ & & $17(17.4)$ & $96(23.3)$ & \\
\hline Metropolitan area & $50(52.3)$ & $116(59.2)$ & & $26(65 . I)$ & $183(61.2)$ & \\
\hline \multicolumn{7}{|c|}{ Socioeconomic income deciles, No. (\%) } \\
\hline $1-2$ & $56(33.4)$ & $90(23.3)$ & 0.283 & $22(37.3)$ & $123(33.4)$ & 0.480 \\
\hline $3-4$ & $19(23.70)$ & $76(33.5)$ & & $9(28.3)$ & $93(25.3)$ & \\
\hline $5-7$ & $42(35.6)$ & $89(31.6)$ & & $22(30.5)$ & $121(32.0)$ & \\
\hline $8-10$ & $8(7.3)$ & $32(11.6)$ & & $3(3.9)$ & $35(9.2)$ & \\
\hline
\end{tabular}

Ethnicity \%

\begin{tabular}{lrrrrrr} 
Speaking any indigenous language & 4.4 & 2.8 & 0.781 & 7.1 & 3.4 & 0.748 \\
\hline Non-speaking indigenous language & 12.4 & 12.0 & 10.3 & 14.6 & \\
\hline Non-indigenous & 83.2 & 85.2 & 82.6 & 82.1
\end{tabular}

\begin{tabular}{lrrrrrr} 
Current smoking, $\%$ & 27.7 & 19.4 & 0.316 & 16.9 & 12.1 & 0.467 \\
\hline Current alcoholism, $\%$ & 39.5 & 32.0 & 0.389 & 23.2 & 22.4 & 0.927 \\
\hline Body mass index $\left(\mathrm{kg} / \mathrm{m}^{2}\right)$ & $29.6(\mathrm{I} .0)$ & $29.9(0.4)$ & 0.756 & $29.2(1.0)$ & $28.9(0.4)$ & 0.748
\end{tabular}

Body mass index $\left(\mathrm{kg} / \mathrm{m}^{2}\right)$, No. (\%)

\begin{tabular}{lllllll}
$<25$ & $23(27.3)$ & $43(16.2)$ & 0.655 & $16(28.2)$ & $63(17.9)$ & 0.387 \\
\hline $25-29.9$ & $45(30.3)$ & $118(45.6)$ & $21(39.7)$ & $151(46.1)$ & $142(36.0)$
\end{tabular}

\begin{tabular}{|c|c|c|c|c|c|c|}
\hline $\mathrm{SBP} \mathrm{mm} \mathrm{Hg}$ & $123.9(2.1)$ & I3I.7 (I.4) & 0.002 & I23.7 (2.6) & $131.9(1.3)$ & 0.005 \\
\hline $\mathrm{DBP}, \mathrm{mm} \mathrm{Hg}$ & $81.1(2.5)$ & $82.1(1.0)$ & 0.731 & $80.3(2.1)$ & $8 \mathrm{I} .4(0.8)$ & 0.623 \\
\hline Hypertension, No. ( \%) & $31(24.9)$ & $154(56.7)$ & $<0.001$ & $19(34.9)$ & $228(56.3)$ & 0.052 \\
\hline Blood pressure $\geq 140 / 90 \mathrm{~mm} \mathrm{Hg}, \%$ & 19.0 & 40.2 & 0.008 & 28.4 & 39.7 & 0.298 \\
\hline Cholesterol, mg/d* & $187.3(5.1)$ & $215.7(6.3)$ & $<0.001$ & $198.3(13.5)$ & $200.5(4.6)$ & 0.877 \\
\hline \multicolumn{7}{|l|}{$\mathrm{HDL}-\mathrm{C}, \mathrm{mg} /\left.\mathrm{d}\right|^{*}$} \\
\hline Men & $35.7(1.2)$ & $37.7(1.3)$ & $\ddagger$ & $34.8(3.2)$ & $36.2(1.0)$ & 0.663 \\
\hline Women & $37.8(1.3)$ & $41.9(1.5)$ & 0.039 & $37.5(2.4)$ & $39.2(\mathrm{I} . \mathrm{I})$ & 0.522 \\
\hline
\end{tabular}




\begin{tabular}{|c|c|c|c|c|c|c|}
\hline & \multicolumn{3}{|c|}{ Cases found during the survey $(n=4 \mid 2)$} & \multicolumn{3}{|c|}{ Self-reported diabetic subjects $(n=428)$} \\
\hline & Aged $\leq 40$ years & Aged $>40$ years & & Aged $\leq 40$ years & Aged $>40$ years & \\
\hline & $n=125$ & $n=287$ & $p$ value & $n=56$ & $n=372$ & $p$ value \\
\hline LDL-C, mg/dl $\dagger$ & 91.7 (3.8) & $107.2(4.2)$ & 0.006 & $96.5(8.8)$ & $97.5(3.3)$ & 0.913 \\
\hline LDL-C $\geq 100 \mathrm{mg} * / \mathrm{dl}, \%$ & 34.5 & 51.1 & 0.068 & 39.9 & $4 I . I$ & 0.915 \\
\hline VLDL-C, mg/dl* & $24.5(0.9)$ & $29.0(1.3)$ & 0.005 & $28.8(2.4)$ & $28.4(1.4)$ & 0.874 \\
\hline Triglycerides, mg/dl* & $14 \mid .7(5.3)$ & $169.4(7.7)$ & 0.003 & $168.9(14.7)$ & $164.8(8.0)$ & 0.807 \\
\hline Fasting glucose, mg/dl* & $176.8(8.7)$ & $196.7(8.2)$ & 0.098 & I85.7 (I4.2) & $190.2(7.2)$ & 0.777 \\
\hline $\mathrm{HbAlc}, \%(n=236)$ & - & - & - & $11.6(1.0)$ & II.6 (0.3) & 0.949 \\
\hline Health service utilization & 14.0 & 13.1 & 0.869 & 18.1 & 22.2 & 0.594 \\
\hline Ophthalmologic examination & - & - & - & 3.4 & 7.9 & 0.215 \\
\hline Renal function examination & - & - & - & 0.0 & 0.8 & - \\
\hline Hypoglycemic medication, \% & - & - & - & 73.4 & 86.5 & 0.107 \\
\hline \multicolumn{7}{|l|}{ Type of hypoglycemic medication, No. ( \%) } \\
\hline Oral hypoglycemic & - & - & - & $37(82.3)$ & $302(92.7)$ & 0.745 \\
\hline Insulin & - & - & - & $6(9.1)$ & $18(5.5)$ & \\
\hline Both & - & - & - & I (8.6) & $8(1.8)$ & \\
\hline Antihypertensive medication, No. (\%) & $I(0.9)$ & $56(69.7)$ & $<0.001$ & $2(45.7)$ & $132(82.5)$ & 0.069 \\
\hline Aspirin use, No. (\%) & - & - & - & $\mathrm{I}(1.9)$ & $24(3.9)$ & 0.456 \\
\hline Statins use, No. (\%) & - & - & - & I (2.8) & $\mathrm{I}(0.2)$ & 0.456 \\
\hline \multicolumn{7}{|l|}{ Diabetic complications } \\
\hline Retinopathy & - & - & - & 7.6 & 15.6 & 0.143 \\
\hline Neuropathy & - & - & - & 3.0 & 14.9 & 0.076 \\
\hline Nephropathy (under dialysis) & - & - & - & 1.9 & $\mathrm{I} . \mathrm{I}$ & 0.665 \\
\hline Myocardial infarction & - & - & - & 6.3 & 1.2 & 0.117 \\
\hline
\end{tabular}

The study was done in Mexico during 2006. Number of subjects with information $n=279,32$ subjects aged $\leq 40$ years and 247 subjects aged $\leq 40$ years All values are means and standard error (s.e.), except when indicated

* 363 cases diagnosed during the survey and 37 I self-reported diabetic subjects

₹ Due to stratum with single sampling unit in this category, it was not possible to estimate the means difference

cardiovascular risk factors $(29.5 \%$ vs $19.9 \%$ respectively, $p<0.05)$ as defined by the National Cholesterol Education Program. ${ }^{14}$ Minor differences were found in the fasting plasma glucose levels between undiagnosed and previously identified cases in both early- and late-onset groups. Among the previously diagnosed cases, the hemoglobin A1c concentrations were abnormally high in both age groups (11.9\% vs. 11.4, $\mathrm{p}=0.49$ ). The majority of cases in both groups were receiving glucose-lowering agents; very few were treated with insulin.

The use of preventive interventions against the diabetes-related chronic complications was low in both age groups. A very small percentage received a statin or low doses of acetyl salicylic acid or underwent regular ophthalmologic or feet exams. In the early-onset group, $7.6 \%$ had retinopathy and $6.3 \%$ suffered a myocardial infarction (by self report). These percentages were not different from that reported by the older group.

Conditions associated with an increase likelihood for having early-onset type 2 diabetes are shown in table IV. Age, body mass index and hypertriglyceridemia were the variables associated with the early-onset phenotype. $\mathrm{A} 5 \mathrm{~kg} / \mathrm{m}^{2}$ difference in the body mass index was associated with a $37 \%$ increment in the risk for having diabetes. For the older group, hypoalphalipoproteinemia, living in urban areas and not being part of a Native American group were associated also with a higher risk for having diabetes. 


\section{Table IV}

AsSOCIATED RISK FACTORS WITH THE PREVALENCE OF DIABETES IN SUBJECTS AGED 40 YEARS AND younger AND subjects older than 40 years of Age. Mexico, ENSANUT 2006

\begin{tabular}{|c|c|c|c|c|c|c|}
\hline & $\begin{array}{l}\text { Aged } 40 \text { years and younger } \\
\qquad(n=288 I)\end{array}$ & & $\begin{array}{l}\text { Older than } 40 \text { years } \\
\text { of age }(n=2623)\end{array}$ & & $\begin{array}{c}\text { Both } \\
(n=5504)\end{array}$ & \\
\hline & $O R(95 \% \mathrm{Cl})$ & $p$ value & OR $(95 \% \mathrm{Cl})$ & $p$ value & OR $(95 \% \mathrm{Cl})$ & $p$ value \\
\hline Age $>40$ years & - & - & - & - & $5.87(4.27-8.05)$ & $<0.001$ \\
\hline Age (per 5 years) & $1.46(1.14-1.86)$ & 0.002 & $1.12(1.06-1.18)$ & $<0.001$ & - & - \\
\hline Sex (women) & $1.02(0.58-1.82)$ & 0.938 & $0.87(0.64-\mathrm{I} .18)$ & 0.377 & $0.93(0.7|-| .2 \mid)$ & 0.574 \\
\hline \multicolumn{7}{|l|}{ Ethnicity } \\
\hline Speaking any indigenous language & 1.0 & - & 1.0 & - & 1.0 & - \\
\hline Non-speaking indigenous language & $1.02(0.39-2.64)$ & 0.972 & $2.03(1.08-3.87)$ & 0.029 & $1.64(0.94-2.87)$ & 0.083 \\
\hline Non-indigenous & $1.08(0.48-2.44)$ & 0.852 & $1.93(1.14-3.28)$ & 0.015 & $1.64(1.02-2.62)$ & 0.039 \\
\hline Urban and metropolitan area & $0.93(0.48-1.79)$ & 0.826 & $1.52(1.11-2.10)$ & 0.010 & $1.31(0.97-1.76)$ & 0.079 \\
\hline Body mass index (per $\left.5 \mathrm{~kg} / \mathrm{m}^{2}\right)$ & $1.37(\mathrm{I} .1 \mathrm{I}-\mathrm{I} .70)$ & 0.004 & $1.13(0.99-1.29)$ & 0.078 & $1.17(1.04-1.32)$ & 0.010 \\
\hline HDL-C (per 10 mg/dl) & $0.86(0.72-1.04)$ & 0.113 & $0.83(0.72-0.96)$ & 0.011 & $0.83(0.73-0.93)$ & 0.002 \\
\hline Triglycerides (per 50 mg/dl) & $1.19(1.05-1.35)$ & 0.005 & $1.37(1.23-1.52)$ & $<0.001$ & $1.32(1.22-1.43)$ & $<0.001$ \\
\hline
\end{tabular}

The study was done in México during 2006

\section{Discussion}

Early-onset type 2 diabetes is a phenotype commonly seen in countries with a high prevalence of type 2 diabetes. It is characterized by a more severe form of the disease and an increased risk for suffering chronic complications. ${ }^{3}$ In México, the number of young adults (aged 20-40 years) with diabetes has increased during the past two decades. Now, early-onset type 2 diabetes is present in $21.5 \%$ of patients with type 2 diabetes. Based on the data reported here, it is estimated that there are 1662870 Mexicans with early-onset type 2 diabetes. The number of cases and their increased risk for having an adverse outcome are reasons for having special attention for this variant of the disease.

In each one of the nation wide population based surveys conducted in Mexico (1994, 2000 and 2006) it has been estimated the proportion of the population with diabetes diagnosed before age 40 . The initial report was a sub-study of the 1994 National Survey of Chronic Diseases (ENEC). ${ }^{5}$ In 1994, the prevalence of diabetes was $6.7 \%$ nationwide and $1.8 \%$ for the age group $20-40$ years. Early-onset type 2 diabetes was present in $14.8 \%$ of the population with diabetes. There were 318400 cases nationwide. Later in 2000, the National Health Survey (ENSA) reported a diabetes national prevalence of $8.2 \%$ and $2.3 \%$ for the age group $20-40$ years. ${ }^{15}$ Earlyonset type 2 diabetes was present in $13.2 \%$ of the popu- lation with diabetes. The data reported here updates the information and demonstrates a remarkable growth of the disease, affecting young adults also (national prevalence $14.4 \%$ and $5.8 \%$ in the $20-40$ years age group). Thus, in a 12 years period the national prevalence of diabetes have had a two-fold increment. The change is bigger for the 20-40 years group, which had a 3.22 fold increment. The number of early-onset type 2 diabetes cases increased from 318400 to 1662870 . As a result, this translates into a greater number of cases and a larger proportion of the affected subjects exposed to the disease for longer periods of time. The end result will be a growth in the incidence of diabetes related chronic complications and a greater number of cases that will retire prematurely due to physical limitations.

The contribution of early-onset type 2 diabetes is now similar in Mexico to the one reported in countries with the highest prevalence of diabetes worldwide. This form of the disease is present in 25\% of the population with diabetes in India, ${ }^{16} 36 \%$ in the Middle East and $26 \%$ in Native Americans living in the US. ${ }^{17}$ Because obesity and unhealthy life styles are very prevalent in Mexican young adults, ${ }^{18}$ it is expected that the number of young adults will continue its growing trend in the years to come.

This population based, nation-wide study allows an unbiased description of the patients with early -onset type 2 diabetes. The clinical profile reported here is similar to that found in previous Mexican surveys.,13 More 
than two thirds of them had a body mass index above $25 \mathrm{~kg} / \mathrm{m}^{2}$. The quality of diabetes care that they received is far from acceptable. They were the group that had the highest prevalence of insulin or oral glucose-lowering treatment of all patients with diabetes. However, the majority of them were severely hyperglycemic. Their mean HDL cholesterol concentration was lower compared to that found in the older group. Nevertheless, they have a lower prevalence of hypercholesterolemia and arterial hypertension. Preventive strategies (i.e., low doses of acetylsalicylic acid, regular ophthalmologic or feet exams) were used in very few cases. All these characteristics contribute to the high rate of chronic complications.

The data reported here suggest that specific programs will be required to improve diabetes care in the early-onset group. They may have specific barriers to achieve the treatment goals. Their education level is higher compared to the older group, making possible to achieve a deeper knowledge about their disease. However, they are in the most productive time of their lives; environmental, economical and social factors may limit their adherence to a healthy lifestyle or to the medication. Our health system should design treatment programs that provide solutions to individuals with limited time to visit a medical unit and without the self-recognition of being at risk of having chronic complications. Translational research is urgently needed in this area.

A large percentage $(70 \%)$ of the early-onset group ignored their condition. Several conditions were independently associated with early-onset type 2 diabetes. Obesity, age and hypertriglyceridemia increased the risk for having this entity. This information will be useful for clinicians to select young individuals in which diabetes screening is required.

In conclusion, early-onset type 2 diabetes is a form of diabetes with important public health implications. In México, the number of young adults (aged 20-40 years) with diabetes has increased five times during the past two decades. Now, early-onset type 2 diabetes is present in $21.5 \%$ of patients with type 2 diabetes. A great effort will be required to educate the public and primary care physicians in order to prevent the increase in the number of cases and provide them the best possible treatment.

\section{Acknowledgments}

The authors would like to thank the support from Sanofi-Aventis for an unrestricted grant that contributed to the biochemical analysis of this sub-sample.

\section{Conflicts of interest}

We declare that we have no conflicts of interest.

\section{References}

I. Rull JA,Aguilar-Salinas CA, Rojas R, Rios-Torres JM, Gómez-Pérez FJ, Olaiz G. Epidemiology of type 2 diabetes in Mexico. Arch Med Res 2005; 36: 188-196.

2. García-García E,Aguilar-Salinas CA, Tusié-Luna MT, Rull-Rodrigo JA. Early-onset type 2 diabetes in México. Isr Med Assoc J 2002;4:444-448. 3. Pavkov ME, Bennett PH, Knowler WC, Krakoff J, Sievers ML, Nelson RG. Effect of youth-onset type 2 diabetes mellitus on incidence of end-stage renal disease and mortality in young and middle-aged Pima Indians. JAMA 2006;296:42I-426.

4. O'Rahilly S, Spivey RS, Holman RR, Nugent Z, Clark A, Turner RC. Type II diabetes of early onset: A distinct clinical and genetic syndrome? Br Med J 1987;294:923-928.

5. Aguilar-Salinas CA, Rojas R, Gómez-Pérez FJ, García E,Valles V, RíosTorres JM, et al. Early-onset type 2 diabetes in a Mexican, populationbased, nation-wide survey:Am J Medicine 2002;1 I 3:569-574.

6. Rosenbloom AL, Young RS, Joe JR, Winter WE. Emerging epidemic of type 2 diabetes in youth. Diabetes Care 1999; 22:345-354.

7. Kadiki OA, Reddy MR, Marzoouk AA. Incidence of insulin dependent diabetes and non insulin dependent diabetes (0-34 years at onset) in Benghazi, Libya. Diabetes Res Clin Pract 1996;32:165-173.

8. Tan KC, Mackay IR, Zimmet PZ, Hawkins BR, Lam KS. Metabolic and immunologic features of Chinese patients with atypical diabetes mellitus. Diabetes Care 2000;23:335-338.

9. Keenan H, el Deirawi K, Walsh M, Grover VV,Alva E, Onyemere K, et al.Are trends in diabetes incidence changing for minority children? Ann Epidemiol 2000;10:459-463.

I0. Petitti DB, Imperatore G, Palla SL, Daniels SR, Dolan LM, Kershnar AK, et al. SEARCH for Diabetes in Youth Study Group.Serum lipids and glucose control: the SEARCH for Diabetes in Youth study.Arch Pediatr Adolesc Med. 2007;161:159-165.

II. Lee SC, Ko GT, Li JK, Chow CC,YeungVT, Critchley JA, et al.Factors predicting the age when type 2 diabetes is diagnosed in Hong Kong Chinese subjects. Diabetes Care 200I;24:646-649.

12. Bessen Daniel H. Update on Obesity J Clin Endocrinol Metab 2008; 93:2027-2034.

13. Expert Committee on Diagnosis and Classification of Diabetes Mellitus. Report of the Expert Committee on Diagnosis and Classification of Diabetes Mellitus. Diabetes Care 1997;20:I I83-I 197.

14. Expert Panel on detection, evaluation and treatment of high blood cholesterol in adults. Executive summary of the third report of the national cholesterol education program (NCEP) expert panel on detection, evaluation and treatment of high blood cholesterol in adults (adult treatment panel III) JAMA 200I; 285: 2486-2497

I5. Aguilar-Salinas CA, Velazquez-Monroy O, Gómez-Pérez FJ, Gonzalez Chávez A, Lara-Esqueda A, Molina-Cuevas V, et al. Characteristics of the patients with type 2 diabetes in Mexico: results from a large populationbased, nation-wide survey. Diabetes Care 2003:26:202I-2026

16. Ramachandran A, Snehalatha C, Kapur A, Vijay V, Mohan V, Das AK, et al. Diabetes Epidemiology Study Group in India (DESI). High prevalence of diabetes and impaired glucose tolerance in India: National Urban Diabetes Survey. Diabetologia 200 I,44:1094-I I0I.

17. Rios-Burrows N, Geiss L, Engelgau M,Acton K. Prevalence of diabetes among native American and Alaska natives 1990-1997. Diabetes Care 2000:23:1786-1790.

18. Córdova-Villalobos JA, Barriguete-Meléndez JA, Lara-Esqueda A, Barquera S, Rosas-Peralta M, Hernández-Avila M, et al. Chronic noncommunicable diseases in Mexico: epidemiologic synopsis and integral prevention. Salud Publica Mex 2008;50:419-427. 